\title{
Asymptomatic, Nonsustained Ventricular Tachycardia in Myotonic Dystrophy Type 1 Detected with a Loop Recorder
}

\author{
Josef Finsterer $^{b}$ Claudia Stöllberger ${ }^{a} \quad$ Marion Avanzini ${ }^{a} \quad$ Elfriede Prager ${ }^{c}$ \\ Franz Weidinger ${ }^{a}$
}

a Second Medical Department, ${ }^{\mathrm{b}}$ Krankenanstalt Rudolfstiftung, Vienna, and ${ }^{\mathrm{C}}$ Krankenhaus Oberpullendorf, Oberpullendorf, Austria

Cardiac involvement is a dominant feature of myotonic dystrophy type 1 (MD1) [1]. Cardiac involvement in MD1 manifests as impulse generation or impulse conduction disturbances or cardiomyopathy [1]. Since cardiac involvement predicts the outcome of these patients $[2,3]$, it is important to detect cardiac involvement as soon as possible after establishing the neurological diagnosis to initiate adequate cardiac therapy. Though ventricular tachyarrhythmias (VTs) are a frequent finding in MD1 patients [3-6], they are usually detected only after patients have become symptomatic. Asymptomatic, nonsustained VT is usually detected only by 24 -hour ambulatory ECG or loop recording as in the following case.

\section{Case Report}

The patient is a 42-year-old, HIV-negative Caucasian male, in whom MD1 was diagnosed at age 31 years, based upon family history, clinical findings and molecular genetic investigations. Since age 6 years he developed slowly progressive dysarthria and since age 14 a foot drop bilaterally. Muscle enzymes were found to be elevated for the first time at age 31 . Clinical neurologic investigation at age 42 years revealed severe dysarthria, bilateral ptosis, ophthalmoparesis, myopathic face, diffuse weakness of the upper limbs with distal predominance (M3+ to M4+), weakness for hip flexion bilaterally (M5-), and for foot extension and flexion bilaterally (M2 and M4-), hyperextensible joints, absent tendon reflexes, hypotonia, ataxia, and a positive Gower's sign. Creatine kinase was $60 \mathrm{U} / \mathrm{l}$ (normal: <171 U/l). Hb A $1 \mathrm{c}$ was $6.4 \%$ (normal: 3.5-6.0\%). Triglycerides and cholesterol were elevated. Ophthalmologic investigations revealed mild cataract and a CT scan of the brain showed moderate widening of the ventricles and a considerable falx meningioma. Nerve conduction studies disclosed polyneuropathy. Needle electromyography showed typical abnormal spontaneous activity and a myogenic motor unit architecture. Analysis for mutations in the DMPK gene on chromosome $19 q 13.3$ revealed a CTG-repeat expansion of 1,333 repeats in nuclear DNA from blood lymphocytes. The mutation was also found in his brother $(1,333 \mathrm{re}$ peats). His mother was clinically affected as well, had developed left bundle-branch block, and had died at age 55 years from sudden cardiac death.

His medical history was negative for arterial hypertension, diabetes, angina pectoris, coronary heart disease, dyspnea, leg edema, syncope, or palpitations. The patient was first investigated for cardiac involvement at age 31 years, revealing normal P-Q interval $(0.18 \mathrm{~ms})$ and ST elevation on ECG and slight tricuspid insufficiency on echocardiography. At age 36 years cardiologic investigation revealed tricuspid insufficiency, an E/A ratio $<1$, and episodes of bradycardia ( $\mathrm{HR}<50$ / min) on 24-hour ambulatory ECG. At age 41 years, physical examination was normal. Blood pressure was 120/70 $\mathrm{mm} \mathrm{Hg}$. The ECG showed sinus rhythm, an AV block I (P-Q interval $0.21 \mathrm{~ms}$ ) and absent $\mathrm{R}$ progression between V1 and V4. Echocardiography was normal. Since 24-hour ambulatory ECG revealed a P-Q interval of $200 \mathrm{~ms}$ and 204 episodes of bradycardia and since his mother had died from sudden cardiac death, it was decided to implant a loop recorder (Reveal Plus, Model 9526, Medtronic Inc.). During the first 1.5 years no abnormal electrical activity could be recorded although interrogation was carried out every 3 weeks. After almost 2 years, however, interrogation of the loop recorder revealed a VT of 1-min duration following an initializing R-on-T phenomenon (fig. 1) during sleep without obvious clinical manifestations. Following the detection of the VT the patient received an implantable cardioverter defibrillator (ICD) at age 42 . Shortly before implantation of the ICD, recurrent VTs were recorded also during continuous ECG monitoring in the hospital where the implantation of the ICD was scheduled. In addition to the ICD he was regularly taking candesartan. During a follow-up of 3 months, 2 discharges were registered because of VTs.

\section{KARGER}

Fax +41 613061234 E-Mail karger@karger.ch www.karger.com (c) 2008 S. Karger AG, Basel 0014-3022/08/0602-0109\$24.50/0

Accessible online at:

www.karger.com/ene
J. Finsterer, $\mathrm{MD}, \mathrm{PhD}$

Postfach 20

AT-1180 Vienna (Austria)

Tel. +431 71165, Fax +4314781711

E-Mailfifigs1@yahoo.de 
Fig. 1. Loop recording showing R-on-T phenomenon with induction of self-limiting ventricular tachycardia for $1 \mathrm{~min}$. Shortly before this episode recurrent ventricular ectopic beats were recorded.

\section{Discussion}

Cardiac involvement in MD1 includes impairment of impulse generation, including sinus bradycardia, atrial and ventricular ectopic beats, atrial fibrillation, atrial flutter, VT, torsade de pointes, or ventricular fibrillation, or impairment of the cardiac conduction system, including atrioventricular block, left or right anterior hemiblock, Q-T prolongation, or bundlebranch block [6-9]. The prevalence of inducible VTs in MD1 patients is $18 \%$ [10]. Myocardial involvement in MD1 is rare and includes myocardial fibrosis [11], fatty infiltration [11], myocardial thickening [11], or left ventricular hypertrabeculation, also known as noncompaction [12], resulting in left ventricular systolic or diastolic dysfunction [13]. The most com-

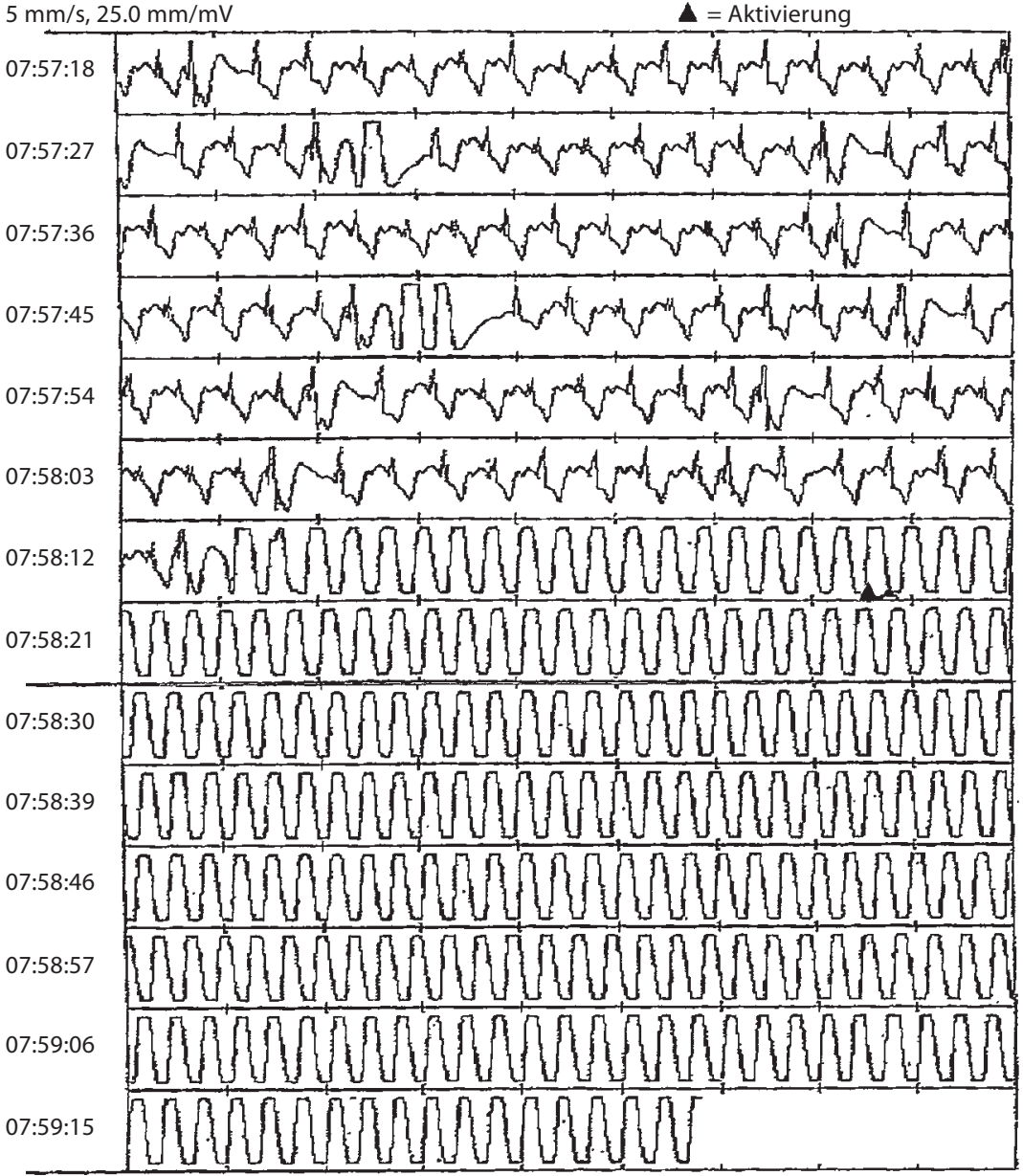

monly reported VT is bundle-branch reentry $[5,14]$ followed by fascicular VT $[15$, 16]. The pathoanatomic substrate of VT is fatty infiltration, interstitial fibrosis, or atrophy and disarrangement of cardiomyocytes $[6,11]$. The alterations result in HisPurkinje conduction delay $[5,17]$. VT can be most easily detected on 24-hour ambulatory ECG or loop recording. The latter has only rarely been carried out in patients with MD1 so far [18]. Though some authors recommend the implantation of ICDs for documented VTs in MD1 patients [6], ICDs have only occasionally been implanted for the prevention of sudden cardiac death in patients with MD1 $[19,20]$. In addition to the implantation of an ICD, ablation of the right bundle has been recommended [13]. Before the availability of ICDs the prevalence of sudden cardiac death was up to $33 \%$ in MD1 patients $[8,11,21]$. Despite ablation, however, some patients with MD1 experience sudden cardiac death.

The presented patient is remarkable for dysarthria as the initial manifestation of MD1, for only mild cognitive impairment despite a CTG repeat number of 1333 , for the late development of cardiac involvement despite considerable repeat expansion, and for the development of asymptomatic, nonsustained VTs, which lastly prompted the implantation of an ICD. Since sudden cardiac death is a prominent feature of cardiac involvement in MD1 [8, $11,21]$, the patient might profit from the implantation of the ICD, particularly in the light of his mother's sudden cardiac death and the recurrence of VTs. However, few data are available about the long-term 
benefit of ICDs implanted to prevent sudden cardiac death in patients with MD1. Whether sudden cardiac death could have been prevented in his mother if she had received an ICD and whether the presented patient will profit from the ICD also on the long run remains questionable. Administration of amiodarone, which was planned by the treating physicians in addition to the ICD, was not recommended to the patient, since previous reports showed that amiodarone can have an arrhythmogenic effect in MD1 patients, leading even to cardiac arrest [22].

This case shows that loop recording may be helpful for the detection of asymptomatic, nonsustained VTs in MD1. Implantation of a loop recorder and close interrogation is strongly recommended in MD1 patients with documented bradycardia, syncope, or a family history positive for sudden cardiac death. Implantation of an ICD may prevent sudden cardiac death in $\mathrm{MD1}$ patients.

\section{References}

$\checkmark 1$ Chebel S, Ben Hamda K, Boughammoura A, Frih Ayed M, Ben Farhat MH: Cardiac involvement in Steinert's myotonic dystrophy. Rev Neurol (Paris) 2005;161:932-939.

2 Finsterer J, Stollberger C, Blazek G, Kunafer M, Prager E: Cardiac involvement over 10 years in myotonic and Becker muscular dystrophy and mitochondrial disorder. Int J Cardiol 2007; 107:374-379.

-3 Casella M, Dello Russo A, Pace M, Pelargonio G, Ierardi C, Sanna T, Messano L, Bencardino G, Valsecchi S, Mangiola F, Lanza GA, Zecchi P, Crea F, Bellocci F: Heart rate turbulence as a noninvasive risk predictor of ventricular tachyarrhythmias in myotonic dystrophy type 1. J Cardiovasc Electrophysiol 2006;17:871-876.
4 Bassez G, Lazarus A, Desguerre I, Varin J, Laforet P, Becane HM, Meune C, Arne-Bes MC, Ounnoughene Z, Radvanyi $H$, Eymard B, Duboc D: Severe cardiac arrhythmias in young patients with myotonic dystrophy type 1. Neurology 2004;63:1939-1941.

5 Merino JL, Carmona JR, Fernandez-Lozano I, Peinado R, Basterra N, Sobrino JA: Mechanisms of sustained ventricular tachycardia in myotonic dystrophy: implications for catheter ablation. Circulation 1998;98:541-546.

6 6 Muraoka H, Negoro N, Terasaki F, Nakakoji T, Kojima S, Hoshiga M, Sugino M, Hosokawa T, Ishihara T, Hanafusa T: Re-entry circuit in ventricular tachycardia due to focal fatty-fibrosis in a patient with myotonic dystrophy. Intern Med 2005;44:129-135.

$\checkmark 7$ Clements SD Jr, Colmers RA, Hurst JW: Myotonia dystrophica: ventricular arrhythmias, intraventricular conduction abnormalities, atrioventricular block and StokesAdams attacks successfully treated with permanent transvenous pacemaker. Am J Cardiol 1976;37:933-935.

8 Posada Rodriguez IJ, Gutierrez-Rivas E, Cabello A: Cardiac involvement in neuromuscular diseases. Rev Esp Cardiol 1997;50:882901.

9 Wolk R: Conduction disturbances and cardiac arrhythmias in myotonic dystrophy: diagnosis and clinical significance in adult populations. Neurol Neurochir Pol 2001;35: 111-118.

10 Lazarus A, Varin J, Babuty D, Anselme F, Coste J, Duboc D: Long-term follow-up of arrhythmias in patients with myotonic dystrophy treated by pacing: a multicenter diagnostic pacemaker study. J Am Coll Cardiol 2002;40:1645-1652.

-11 Nguyen HH, Wolfe JT 3rd, Holmes DR Jr, Edwards WD: Pathology of the cardiac conduction system in myotonic dystrophy: a study of 12 cases. J Am Coll Cardiol 1988;11: 662-671.

12 Finsterer J, Stollberger C, Wegmann R, Jarius C, Janssen B: Left ventricular hypertrabeculation in myotonic dystrophy type 1 . Herz 2001;26:287-290.
13 Ramirez CJ, Rodriguez DA, Velasco VM, Rosas F: Myotonic dystrophy and bundlebranch re-entrant tachycardia. Rev Esp Cardiol 2002;55:1093-1097.

14 Saliba WI, Natale A: Ventricular tachycardia syndromes. Med Clin North Am 2001;85: 267-304.

15 Tamura K, Tsuji H, Matsui Y, Masui A, Hikosaka M, Karakawa M, Iwasaka T, Inada M: Sustained ventricular tachycardias associated with myotonic dystrophy. Clin Cardiol 1996;19:674-677.

16 Berger RD, Orias D, Kasper EK, Calkins H: Catheter ablation of coexistent bundle branch and interfascicular re-entrant ventricular tachycardias. J Cardiovasc Electrophysiol 1996;7:341-347.

17 Grigg LE, Chan W, Mond HG, Vohra JK, Downey WF: Ventricular tachycardia and sudden death in myotonic dystrophy: clinical, electrophysiologic and pathologic features. J Am Coll Cardiol 1985;6:254-256.

$\checkmark 18$ Hadian D, Lowe MR, Scott LR, Groh WJ: Use of an insertable loop recorder in a myotonic dystrophy patient. J Cardiovasc Electrophysiol 2002;13:72-73.

19 Asada M, Suzuki H, Sumitomo M: Anesthetic management for cardioverter defibrillator implantation in a patient with preoperatively undiagnosed myotonic dystrophy. Masui 2001;50:1136-1138.

$>20$ Gardini A, Zagami N, Marchini A, Morandi F, Bianchetti F, Curnis A, Politi A: The electrotherapy of the arrhythmias in 3 cases of myotonic dystrophy (Steinert's disease). Cardiologia 1996;41:1209-1214.

21 Hiromasa S, Ikeda T, Kubota K, Hattori N, Coto H, Maldonado C, Kupersmith J: Ventricular tachycardia and sudden death in myotonic dystrophy. Am Heart J 1988;115:

914-915.
22 Cannom DS, Wyman MG, Goldreyer BN: Clinical and induced ventricular tachycardia in a patient with myotonic dystrophy. J Am Coll Cardiol 1984;4:625-628. 